\title{
Correction to: Public-on-private dual practice among physicians in public hospitals of Tigray National Regional State, North Ethiopia: perspectives of physicians, patients and managers
}

Goitom Gigar Abera ${ }^{* *}$, Yibeltal Kiflie Alemayehu ${ }^{2}$ and Jeph Herrin ${ }^{3}$

\section{Correction}

After the publication of this article [1] it has come to our attention that the author Jeph Herrin was incorrectly included as Jeph Henry. The correct spelling is included in this erratum and the original article has been updated.

\begin{abstract}
Author details
${ }^{1}$ Tigray Regional Health Bureau, Mekelle, Tigray, Ethiopia. ${ }^{2}$ Department of Health Services Management, College of Public Health and Medical Sciences, Jimma University, Jimma, Oromia, Ethiopia. ${ }^{3}$ Yale University School of Public Health, New Haven, CT, USA.
\end{abstract}

Received: 20 November 2017 Accepted: 28 November 2017

Published online: 05 December 2017

\section{Reference}

1. Abera GG, et al. Public-on-private dual practice among physicians in public hospitals of Tigray National Regional State, North Ethiopia: perspectives of physicians, patients and managers. BMC Health Serv Res. 2017;17:713. doi:10.1186/s12913-017-2701-6.

\footnotetext{
* Correspondence: gigar2010@gmail.com

'Tigray Regional Health Bureau, Mekelle, Tigray, Ethiopia

Full list of author information is available at the end of the article
} 